\title{
Drying a Standing Teak Tree using a Solar Kiln Drying Method
}

\author{
Khamtan PHONETIP*, Latsamy BOUPHA, \\ Bounyu PHANOUVONG, Oudone SICHALUENE, \\ Khanxay KHAMMANIVONG and Douangta BOUAPHAVONG
}

\author{
Department of Forest Economics and Wood Technology, Faculty of Forest Science, \\ The National University of Laos, Dong Dok Campus, Vientiane, Lao
}

('Corresponding author's e-mail: khamtanfof@gmail.com)

Received: 16 January 2020, Revised: 23 April 2020, Accepted: 30 May 2020

\begin{abstract}
Understanding the rate of drying of standing trees dried by using a solar kiln drying method could help in predicting the change of moisture content in the tree over a period of drying time. The purpose of this study was to observe the change of moisture content profile in a standing tree during drying. A standing Tectona grandis tree was selected for the experiment with a diameter at breast height of $29 \mathrm{~cm}$ in a mixed-species plantation. The tree was girdled with $20 \mathrm{~cm}$ width at $20 \mathrm{~cm}$ above ground. For the experiment, the tree was wrapped in a transparent plastic sheet and a black plastic sheet was installed at the bottom with an angle of $39{ }^{\circ} \mathrm{C}$ facing Southwest to maximize solar radiation, with the method being modified from the solar kiln method, which is known as a greenhouse type, with 2 layers of plastic cover. The black and white sheets were placed on the inner side for insulation and for collecting heat from the sun's radiation, while the outer layer was transparent, which allowed radiation to propagate unhindered in the black sheet. In this study, a sensor for temperature and relative humidity (DHT22) was attached inside the wrapped plastic and the data recorded every $6 \mathrm{~min}$. The results showed that drying a standing teak tree from an initial average moisture content of $105 \%$ to a constant point of $60 \%$ took 80 days under the maximum of the collected temperature of $46^{\circ} \mathrm{C}$ inside the wrapped plastic; this finding confirmed that the predicted model of recharge and discharge curve was likely accurate.
\end{abstract}

Key words: Solar drying, Drying a standing tree, Moisture content profile, Temperature oscillation, Arduino Uno-solar kiln

\section{Introduction}

Delivering fallen timber (green logs) from plantation sites to sawmills costs high capital, because the green timber contains lots of water. Drying timber practices, such as the air-drying method and kiln drying processes, are usually conducted at sawmills after timber is sawn. Therefore, investigating any possibility to dry timber at plantation sites before delivering to factories is considered, to reduce costs as a result of the lighter weight.

The air-drying method could be one of the available methods to address the above problem. However, logs need to be converted to lumber; otherwise, drying can be time-consuming. Alternatively, drying standing trees could possibly help reducing weight and to crack during the drying process. Traditionally, in Laos, local people collected deadwood to be used as firewood for cooking purposes. When lacking deadwood in the forest, they usually debarked/girdled standing live trees at approximately lower than $1 \mathrm{~m}$ above ground, with a length of $20 \mathrm{~cm}$ longitudinal as a circle of the horizon. After 1 to 2 months, trees were ready to be cut and used as firewood, because the wood was partially dried. The time taken for the tree to be ready to be cut would depend on climatic conditions of different regions and seasons and the diameter of the standing tree. The problem here is how can we control the drying 
parameters, i.e., temperature, relative humidity, and airflow, in an opened yard where the standing trees are located.

A $2 \mathrm{~m}^{3}$ greenhouse type solar kiln (Solarkilns Pty Ltd, Kilsyth, VIC, Australia) has been used in Melbourne, Australia [1-3]. The kiln came with 2 layers of plastic cover. The black and white sheets were placed on the inner side for insulation and for collecting heat from the sun's radiation, while the outer layer was transparent, which allowed radiation to propagate unhindered in the black sheet. Adapting this technology with some modifications may offer productivity for drying standing trees, such as drying time being faster than natural drying and avoiding cracking. There are 2 main points for which it is believed to be able to make modifications. Firstly, a controller unit modification, where unnecessary parts of the original scale of kiln compartment has to be fitted with the actual size and shape of a standing tree; thus, fans for air circulation and water sprayers could be removed. Secondly, applying 2 plastic sheets for the purpose of direct heat propagation is required to fit with the size of a standing tree. This would help to reduce the costs of installation and ease the processes. However, expanding numbers of trees to be dried by this method could lead to higher costs, where the capacity of the controller unit should be improved and upgraded.

It was suggested that tropical latitude has high solar radiation [4] and the prediction of temperature in Vientiane (Laos) using a recharge and discharge curve model found that the maximum temperature could reach $47^{\circ} \mathrm{C}$ at $2 \mathrm{pm}$ [1]. In addition, the lowest ambient equilibrium moisture content (EMC) in Vientiane was around $11-12 \%$ from December to March, and $14 \%$ for April [5]. Thus, drying a standing tree in this region could be appropriate.

Moisture content (MC) profile is well-known as one of the vital drying parameters by drying experts. It assists in understanding the drying rate and timber quality during and at the end of drying. Therefore, understanding the effect of using the proposed technology via experimenting with drying standing trees is required at this initial stage for further improvement. The objective is to observe the change of MC profile during drying a standing tree.

\section{Materials and methods}

\section{Samples and experimental setup}

Teak is one of the timber species that is being increased by area and supply to the wood processing sector in Laos. For instance, in Luang Prabang Province, 15,000 ha of teak (Tectona grandis L. fil.) has been established. Teak is encouraged for domestic wood processing aiming to mobilize this teak resource as an alternative to timber from natural forests [6]. The total areas of teak plantation in Lao PDR vary, with estimates between 40,000 ha [7]. Therefore, understanding drying of this timber species could contribute to reduction in costs of the transportation of logs from plantation areas to sawmills and processing sites. Thus, a Tectona grandis tree was selected for this experiment, conducted at the Faculty of Forest Science, National University of Laos (NUoL), from February until June, this period offering high solar radiation, as suggested by Simpson andTschernitz [4], and SSE [8] and is also known as the dry season in Laos [9]. Also, Phonetip et al. [5] found that the Faculty of Forestry Sciences is one of the most suitable locations for drying timber using solar kilns. The tree was located at geographical coordinates of $18^{\circ} 0.2^{\prime} 21^{\prime \prime} \mathrm{N}$ and $120^{\circ} 37^{\prime} 45^{\prime \prime E}$, with $108 \mathrm{~m}$ above sea level. The diameter at the high breasts was $29 \mathrm{~cm}$, and it was $18 \mathrm{~m}$ high.

The experimental set-up included 2 parts; a data acquisition unit (Figure 2) and a compartment as shown in Figure 1. The drying compartment used a clear plastic sheet covering the tree's stem from below the $1^{\text {st }}$ branch under its canopy with a square shape (steel frame) of $60 \times 60 \mathrm{~cm}^{2}$, down to the bottom of the tree, with an attachment of a closed-black plastic sheet with steel frame of $300 \times 300 \mathrm{~cm}^{2}$ with a suggested angle of $39^{\circ}$ where maximum solar radiation could be received between 10 am to $3 \mathrm{pm}$ [10]. Each corner of the steel frame was tight with lashes that made contact with the ground to ensure it could withstand wind. The top of the wrapped plastic was open, allowing water to evaporate and then removed by an exhaust fan. 


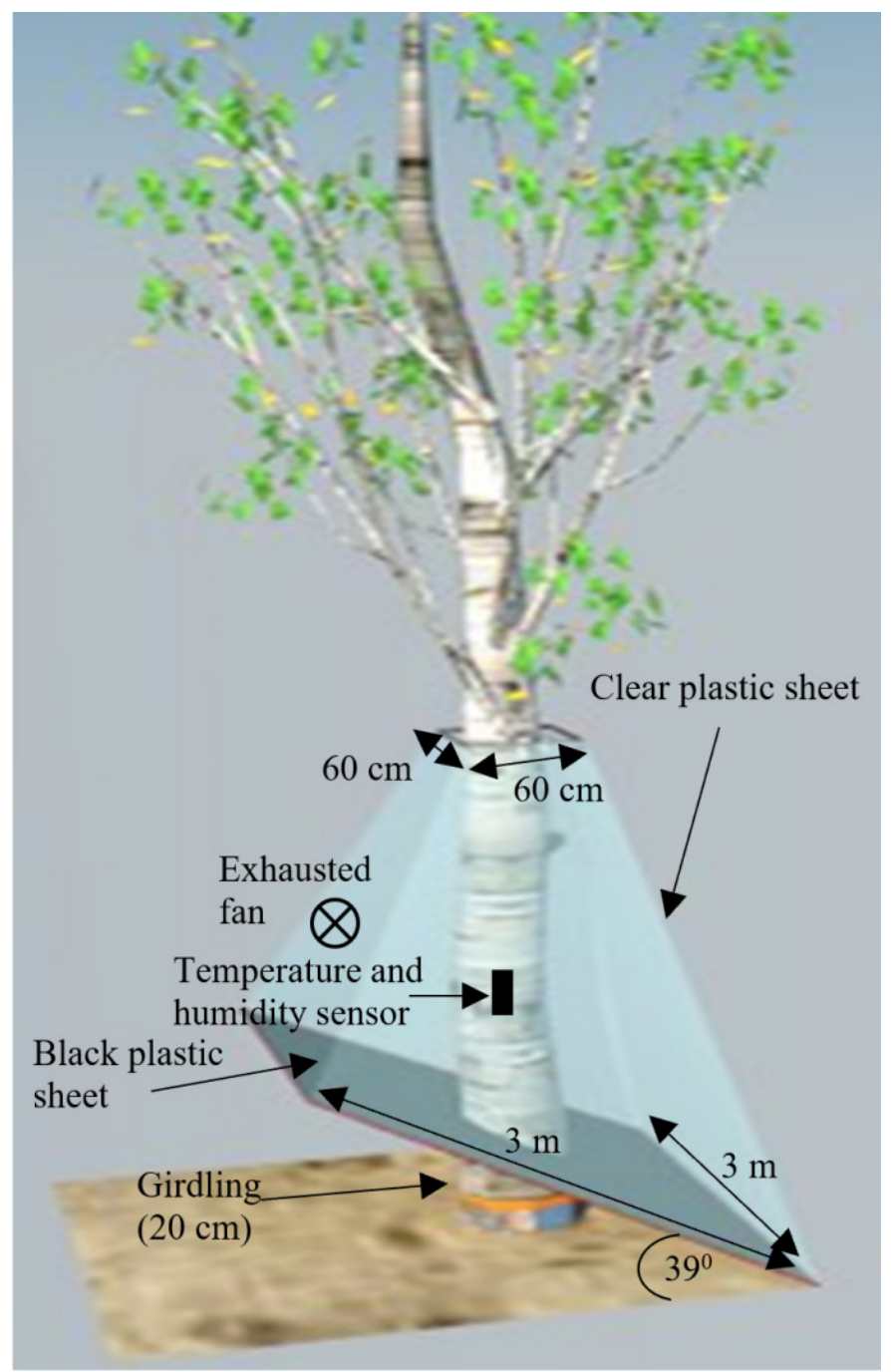

Figure 1 Drying compartment set-up.

\section{Data acquisition unit}

The data acquisition unit (Figure 2) was invented by Khamtan Phonetip using an Arduino Uno with a sensor of DHT22. The accuracy of the DHT22 sensor was as follows: humidity was $\pm 2 \%$ RH (Max \pm 5 $\% \mathrm{RH})$, and temperature was $< \pm 0.5$ Celsius [11]. An exhaust fan of $8 \times 8 \mathrm{~mm}^{2}$ was used for venting humidity. The temperature and relative humidity were recorded every 6 minutes and stored on an SD card. The RH was set and controlled by an exhaust fan at $25 \%$, which was "Off" mode, and "On" when the RH was higher than the set value from the start until the end of the experiment. 

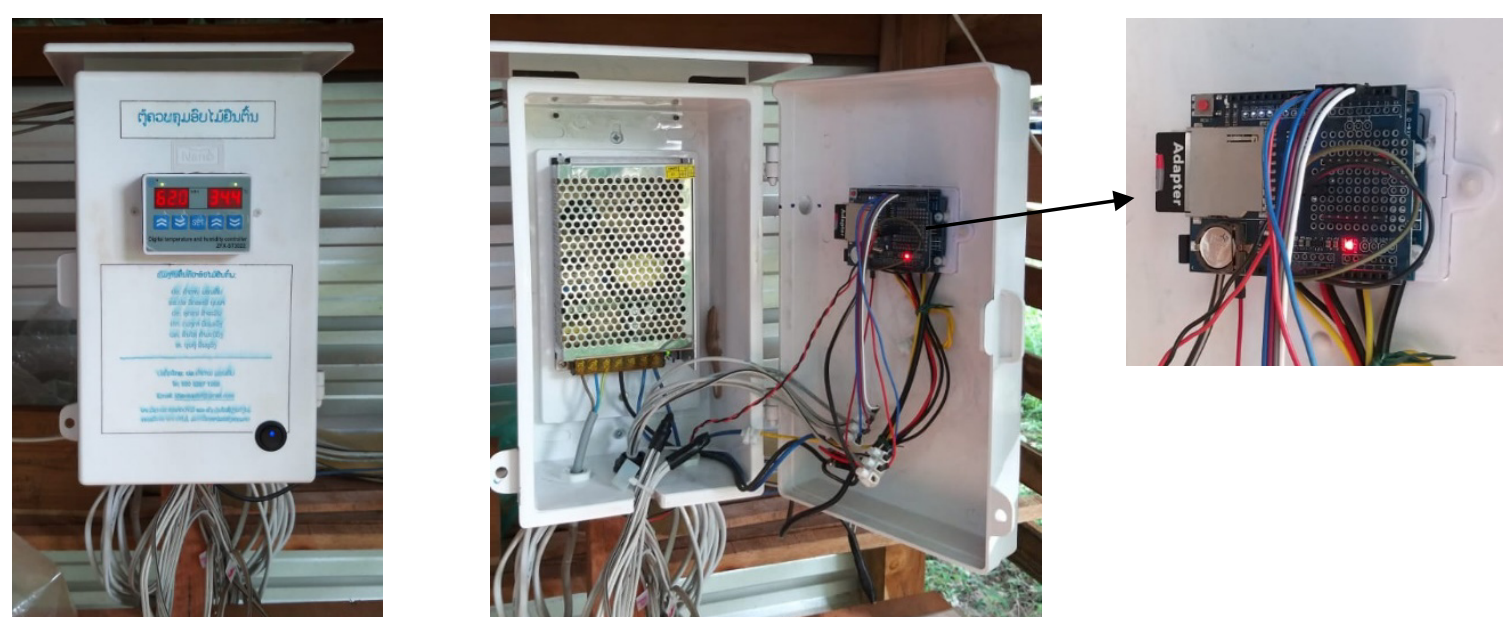

Figure 2 Data acquisition unit.

\section{Samples collection}

The girdling of the standing tree was done at $20 \mathrm{~cm}$ above 0 ground, with $20 \mathrm{~cm}$ width and $2 \mathrm{~cm}$ depth. The monitoring MC profile was done using an increment borer. It was used to drill into the standing Tectona grandis tree from 1 edge through the pith to another edge of the tree in order to take specimens. The method of taking samples was as shown in Figure 3. Each drill sample was split into 9 specimens for measuring the MC. Specimen Nos. 1, 2, 8, and 9 were case areas located near the bark of the tree. Specimen Nos. 4 and 5 were core areas that covered the pith and the center part of the tree. After that, $\mathrm{MC}$ values were calculated based on the Oven-dry Laboratory Method. Samples were taken from the bottom, then moved up to the next spot vertically at $2 \mathrm{~cm}$ hole distancing for every 10 days and continued until constant values of MC were reached.

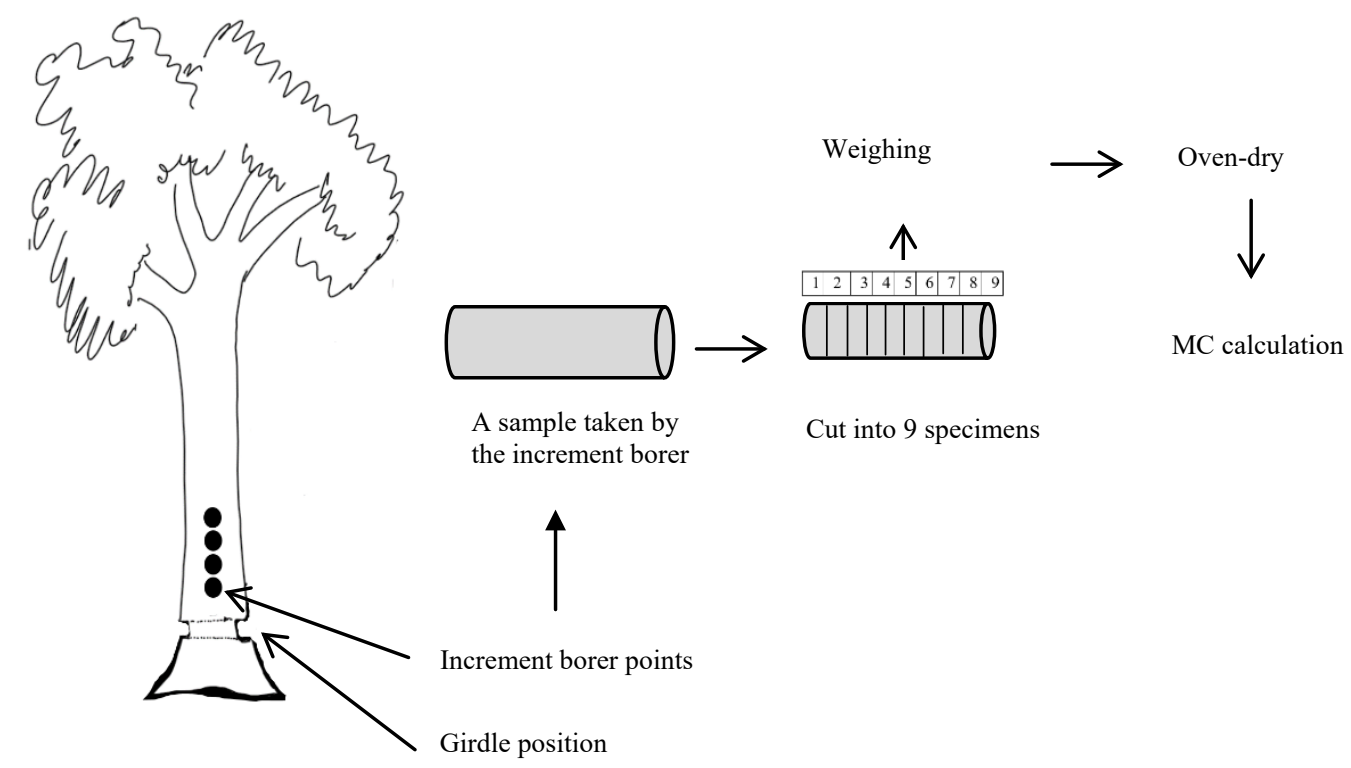

Figure 3 Measuring MC profile. 


\section{Results and discussion}

\section{Drying conditions}

Figure 4 shows that the mean minimum temperature inside the drying compartment was $25^{\circ} \mathrm{C} \pm 1$ at $6 \mathrm{am}$, and the mean maximum temperature was $41{ }^{\circ} \mathrm{C} \pm 5$ at $2 \mathrm{pm}$. This means that the maximum temperature was $46{ }^{\circ} \mathrm{C}$, which approximately reached the results $\left(47^{\circ} \mathrm{C}\right)$ from a previous study that used a recharge and discharge curve model [12], while the maximum ambient temperature was found to be 35 ${ }^{\circ} \mathrm{C}$ [13]. Since the drying unit did not have a supplemental heating supply, the only way the heat came was from the black plastic that was stored at the bottom of the teak tree inside the compartment (Figure 1). The temperature fluctuated from time to time and day to day, depending on diurnal conditions; therefore, the difference in peak temperature was found to be $10{ }^{\circ} \mathrm{C}$.

The mean lowest relative humidity was at $50 \% \pm 25$ from 1.30 to $4.30 \mathrm{pm}$, and the highest RH was $95 \% \pm 5$ at $7.00 \mathrm{am}$. The RH was able to reach the set point of $25 \%$ from 2 to $5 \mathrm{pm}$. This value of RH inside the drying compartment was found to be lower than the ambient condition of $35 \%$ predicted by [8].

Considering the maximum temperature of $46^{\circ} \mathrm{C}$ inside the compartment with the range of relative humidity value of $25-50 \%$, the conditions could allow EMC at $4.5-8.5 \%$, as per the EMC chart [14]. The EMC values were found to be much lower than the ambient conditions (11-12\%) from December to March, and $14 \%$ for April [5].

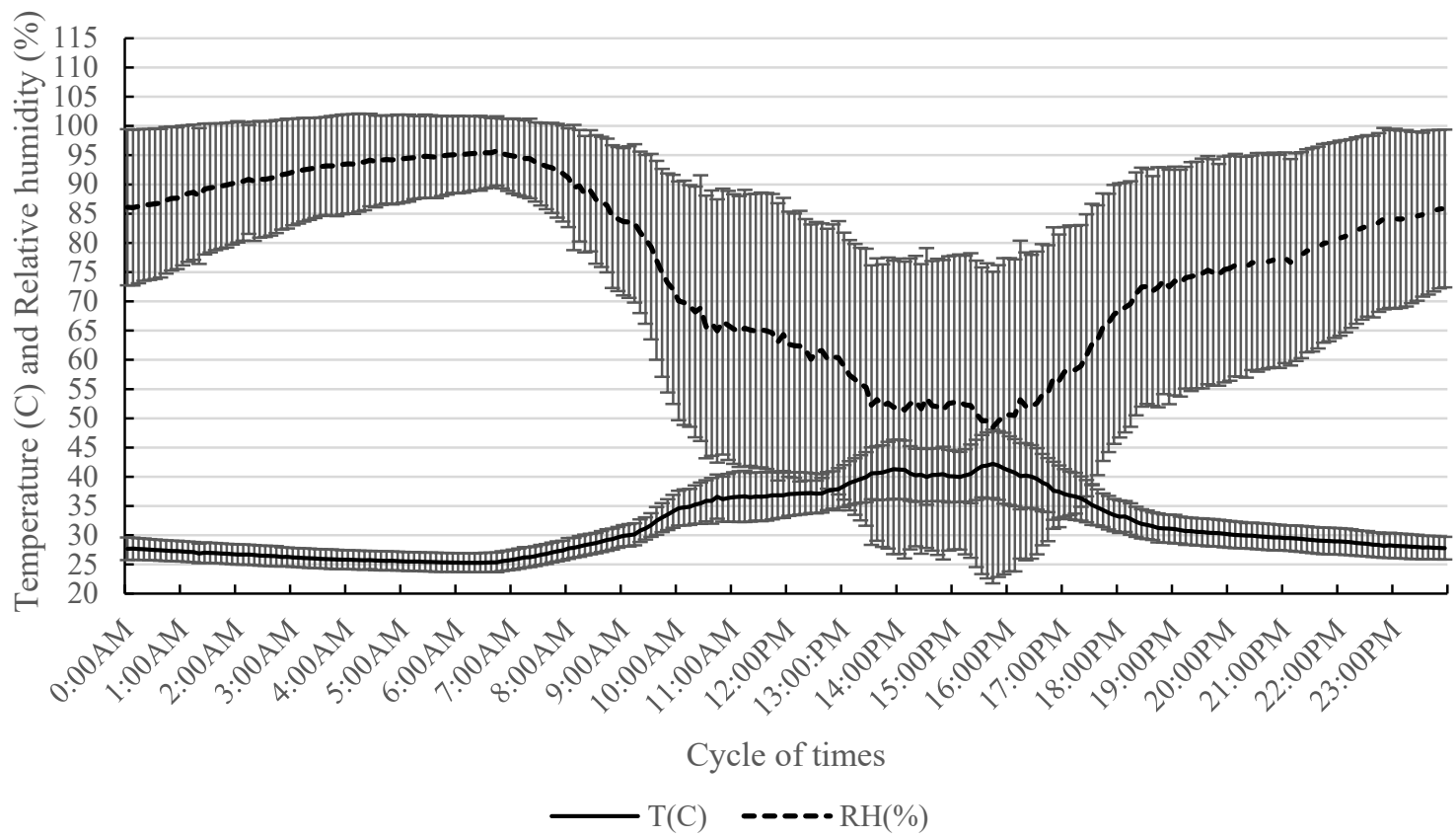

Figure 4 Oscillation of temperature and relative humidity conditions inside the drying compartment during $24 \mathrm{~h}$ cycles for 80 days.

\section{Moisture content profile in the tree during drying}

The variations of MC change within the standing tree ( 9 specimens) showed that the mean initial $\mathrm{MC}$ was $105 \% \pm 7$, where the case $\mathrm{MC}$ was $102 \%$ and the core $\mathrm{MC}$ was $108 \%$. After that, the measurement of MC at 70 days (MC70), 80 days (MC80), 90 days (MC90), and 100 days (MC100) was calculated and plotted, as in Figure 5. Drying the standing Tectona grandis tree took 80 days from the initial average $\mathrm{MC}$ of 105 to $60 \%$, where the MC was constant. 
http://wjst.wu.ac.th

The case MC started from 102 to $52 \%$ and 108 to $68 \%$ at the core of the tree (Figure 6). It decreased by $0.6 \%$ day at the case and $0.5 \%$ /day on average at the core of the tree. The drying experiment was conducted over 100 days, but the MC was found at constant points from 80 days of 52 and $68 \%$ for the case and core, respectively.

According to drying conditions, shown in Figure 4, the tree should have reached the lowest MC of $4.5 \%$, rather than a constant point at $60 \%$. Moisture content migrates from the pith to the bark of the tree and evaporates, which could be caused by 2 reasons. The bark could be acting as insulation, and the top of clear wrapped plastic was open (Figure 1). The insulation could stop water evaporating from sapwood, while the open plastic from the top near the canopy could receive rain (water) which could be absorbed by the tree bark. This meant that the tree could increase its MC when the rain came, so causing slow drying of the standing tree by keeping the inner at a higher MC than the outer part. In this case, the EMC of this region would not be affected by this kind of drying experiment.

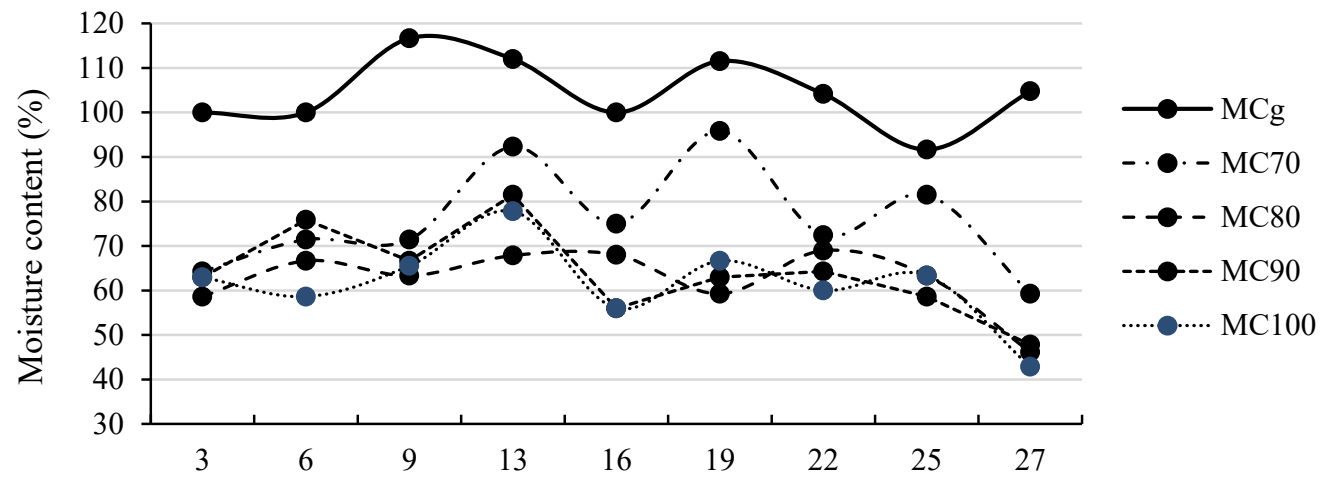

Distance of the tree diameter $(\mathrm{cm})$ from one edge to another

Figure $5 \mathrm{MC}$ decrement by specimens against drying time.

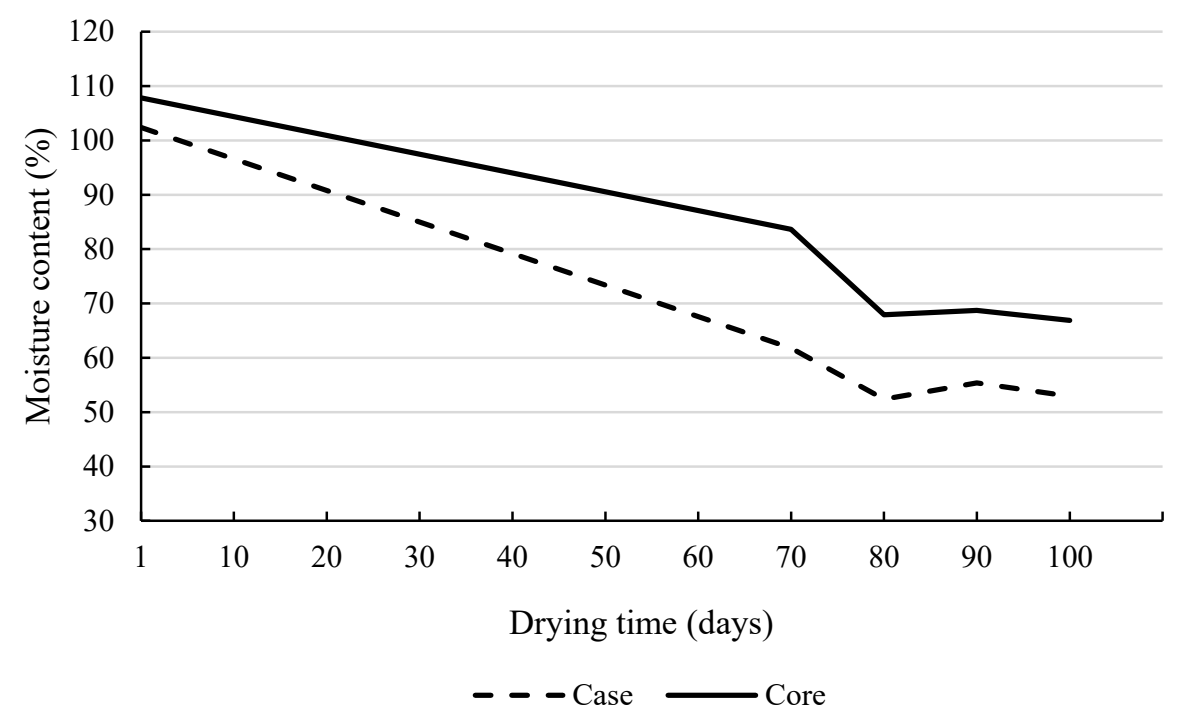

Figure $6 \mathrm{MC}$ decrement by the case and core area against drying time. 
Traditionally, timber is partially air-dried to $57-68 \%$ [15] at the sawmill before being kiln-dried. This implied that the green weight teak tree had decreased significantly over 80 days. Thus, delivering teak logs at $60 \%$ of MC from plantation to sawmill could help reduce the cost of transportation, with less and impact on roads and fewer carbon emissions.

\section{Conclusions}

Drying a standing teak tree from an initial average moisture content of $105 \%$ to a constant point of $60 \%$ took 80 days under the oscillation of temperature $25^{\circ} \mathrm{C} \pm 1$ at 6 am and mean maximum temperature of $41{ }^{\circ} \mathrm{C} \pm 5$ at $2 \mathrm{pm}$, with fluctuating $\mathrm{RH}$ of $50 \% \pm 25$ from 1.30 to $4.30 \mathrm{pm}$ and the highest RH of $95 \%$ \pm 5 at nighttime inside wrapped plastic. The initial mean $\mathrm{MC}$ of the case was $102 \%$, decreasing to $52 \%$, and core $108 \%$, decreasing to $68 \%$. This finding confirmed that the predicted model of recharge and discharge curve for the temperature inside the solar kiln based on Laos' climatic conditions was likely accurate (this prediction being $47^{\circ} \mathrm{C}$ ).

\section{Acknowledgements}

The authors thank the Faculty of Forest Sciences for providing funds for this research and allowing us to conduct the experiment with a teak tree located inside the Faculty campus.

\section{References}

[1] K Phonetip, GI Brodie, B Ozarska, and B Belleville. Drying timber in a solar kiln using an intermittent drying schedule of conventional laboratory kiln. Dry. Technol. 2018; 37, 1300-12.

[2] K Phonetip, B Ozarska, G Harris, B Belleville, and GI Brodie. Quality assessment of the drying process for Eucalyptus delegatensis timber using greenhouse solar drying technology. Eur. J. Wood Wood Prod. 2018; 77, 57-62.

[3] K Phonetip, B Ozarska, B Belleville and G Brodie. Using a conventional laboratory kiln as a simulation of solar cyclic drying. IUFRO Division 5 Conference/SWST. In: Proceedings of the $60^{\text {th }}$ International Convention Forest Sector Innovations for a Greener Future, Vancouver, Canada, 2017, p. 12-16.

[4] W Simpson and J Tschernitz. Solar dry kiln for tropical latitudes. For. Prod. J. 1984; 34, 25-34.

[5] K Phonetip, B Ozarska, GI Brodie, B Belleville and L Boupha. Applying a GIS-based fuzzy method to identify suitable locations for solar kilns. BioResources 2018; 13, 2785-99.

[6] HF Smith, S Ling and K Boer. Teak plantation smallholders in Lao PDR: What influences compliance with plantation regulations? Aust. For. 2017; 80, 178-87.

[7] SJ Midgley, PR Stevens and RJ Arnold. Hidden assets: Asia's smallholder wood resources and their contribution to supply chains of commercial wood. Aust. For. 2017; 80, 10-25.

[8] SSE. Available at: https://eosweb.larc.nasa.gov, accessed August 2019.

[9] Selective Asia. Available at: https://www.selectiveasia.com/laos-holidays/weather, accessed October 2019.

[10] Sun path chart program. Available at: http://solardat.uoregon.edu/SunChartProgram.php, accessed April 2020.

[11] T Liu. Digital-output relative humidity \& temperature sensor/module DHT22. Aosong Electronics.

[12] K Phonetip, GI Brodie, B Ozarska and B Belleville. Drying timber in a solar kiln using an intermittent drying schedule of conventional laboratory kiln. Dry. Technol. 2019; 37, 1300-12.

[13] SSE. Available at: https://asdc-arcgis.larc.nasa.gov/sse, accessed September 2017.

[14] AFRDI. Australian timber seasoning manual. Launceston, Tas: The Institute, Australia, 1997.

[15] A Redman. Drying operations and dried quality study, and recommendations for improved drying efficiency. VALTIP2, 2016. 